Washington University School of Medicine Digital Commons@Becker

$1-1-2019$

\title{
Primary adenoid cystic carcinoma of the liver: Case report and review of the literature
}

\author{
Jianbo Zhang \\ Zhengzhou University \\ Yuanyuan Wang \\ Zhengzhou University \\ Dengfeng Cao \\ Washington University School of Medicine in St. Louis
}

Follow this and additional works at: https://digitalcommons.wustl.edu/open_access_pubs

Please let us know how this document benefits you.

\section{Recommended Citation}

Zhang, Jianbo; Wang, Yuanyuan; and Cao, Dengfeng, "Primary adenoid cystic carcinoma of the liver: Case report and review of the literature." Annals of Hepatology : Official Journal of the Mexican Association of Hepatology. 18, 1. 209 - 214. (2019).

https://digitalcommons.wustl.edu/open_access_pubs/8194

This Open Access Publication is brought to you for free and open access by Digital Commons@Becker. It has been accepted for inclusion in Open Access Publications by an authorized administrator of Digital Commons@Becker. For more information, please contact vanam@wustl.edu. 


\title{
Primary Adenoid Cystic Carcinoma of the Liver: Case Report and Review of the Literature
}

\author{
Jianbo Zhang, ${ }^{\star}$ Yuanyuan Wang, ${ }^{\star}$ Dengfeng Cao**
}

* Department of Pathology, the Affiliated Cancer Hospital of Zhengzhou University \& Henan Provincial Cancer Hospital, Zhengzhou, Henan Province, China. ** Department of Pathology and Immunology, Washington University School of Medicine, Saint Louis, MO, USA.

\begin{abstract}
Adenoid cystic carcinoma (ACC) is an uncommon tumor primarily occurring in the salivary glands and is relatively rare in other sites. In the liver, only one primary adenoid cystic carcinoma has been reported in the English literature. Here we presented a primary hepatic adenoid cystic carcinoma in a 44 years old male. We described its histopathologic features and its immunohistochemical profile, and reviewed the literature. The surgical treatment and patient follow up information was also presented.
\end{abstract}

Key words. Adenoid cystic carcinoma. Liver. Primary.

\section{INTRODUCTION}

Adenoid cystic carcinoma (ACC) is a rare tumor mainly occurring in the salivary glands (parotid glands, submandibular glands, sublingual glands, and minor salivary glands). ${ }^{1,2}$ ACC uncommonly may also arise in other body sites including lacrimal glands, ${ }^{3}$ upper respiratory system, ${ }^{4-5}$ breast, ${ }^{6}$ prostate ${ }^{7}$ and female low reproductive organs. ${ }^{8}$ Primary ACC in the liver is extremely rare with only one case having been reported in the literature. ${ }^{9}$ Here we present an unusual case of ACC in the liver with no tumor found in other organs except involvement of adjacent diaphragm and omentum. We favor this is a primary adenoid cystic carcinoma in the liver. We performed histopathologic and immunohistochemical analysis and provided treatment and followup information.

\section{CASE REPORT}

This is a 44 years old male presenting with upper abdominal distension for three months and upper abdominal pain for one week. Physical examination revealed the liver to be extending to $10 \mathrm{~cm}$ beyond the rib contour. No liver tenderness was present. Physical examination revealed no jaundice or spider angioma (spider nevus). There was no edema in his body. Superficial lymph nodes were not pal- pable. Ultrasound examination showed an abnormal liver with a mass in the left lobe with a mixed echo signal and no increased blood flow (Figure 1A). A subsequent computerized tomography examination (Figure $1 \mathrm{~B}$ ) revealed a $21.0 \times 16.0 \mathrm{~cm}$ mass with an irregular border in the left lobe of the liver. His complete blood counts, total bilirubin, and protein levels were all within normal ranges. Liver enzymes alanine transaminase (ALT) and aspartate aminotransferase (AST) were within normal ranges but gamma-glutamyl transferase (GGT) was elevated (155 U/L, normal range 7-50 U/L). His HbsAg test was negative. Serum AFP and CEA levels were within normal ranges. CA19.9 was elevated to $108.6 \mathrm{U} / \mathrm{mL}$ (normal 0-30 U/mL).

The preoperative clinical diagnosis was a primary liver cancer and a surgery was scheduled. During the operation, a huge liver tumor was found in the left hepatic lobe with invasion into the liver capsule and adhering to the diaphragm. The liver left lobe with adjacent capsule and diaphragm was resected. A portion of omentum was also resected.

The resected liver tissue measured $24.0 \times 20.0 \times 12.0$ $\mathrm{cm}$ and sectioning revealed a $22.0 \times 18.0 \times 11.0 \mathrm{~cm}$ mass. The mass had a solid and cystic cut surface with a blurry border. Microscopically the tumor demonstrated predominantly cribriform growth pattern (90\% area) with a minor component of tubular and solid growth pattern 

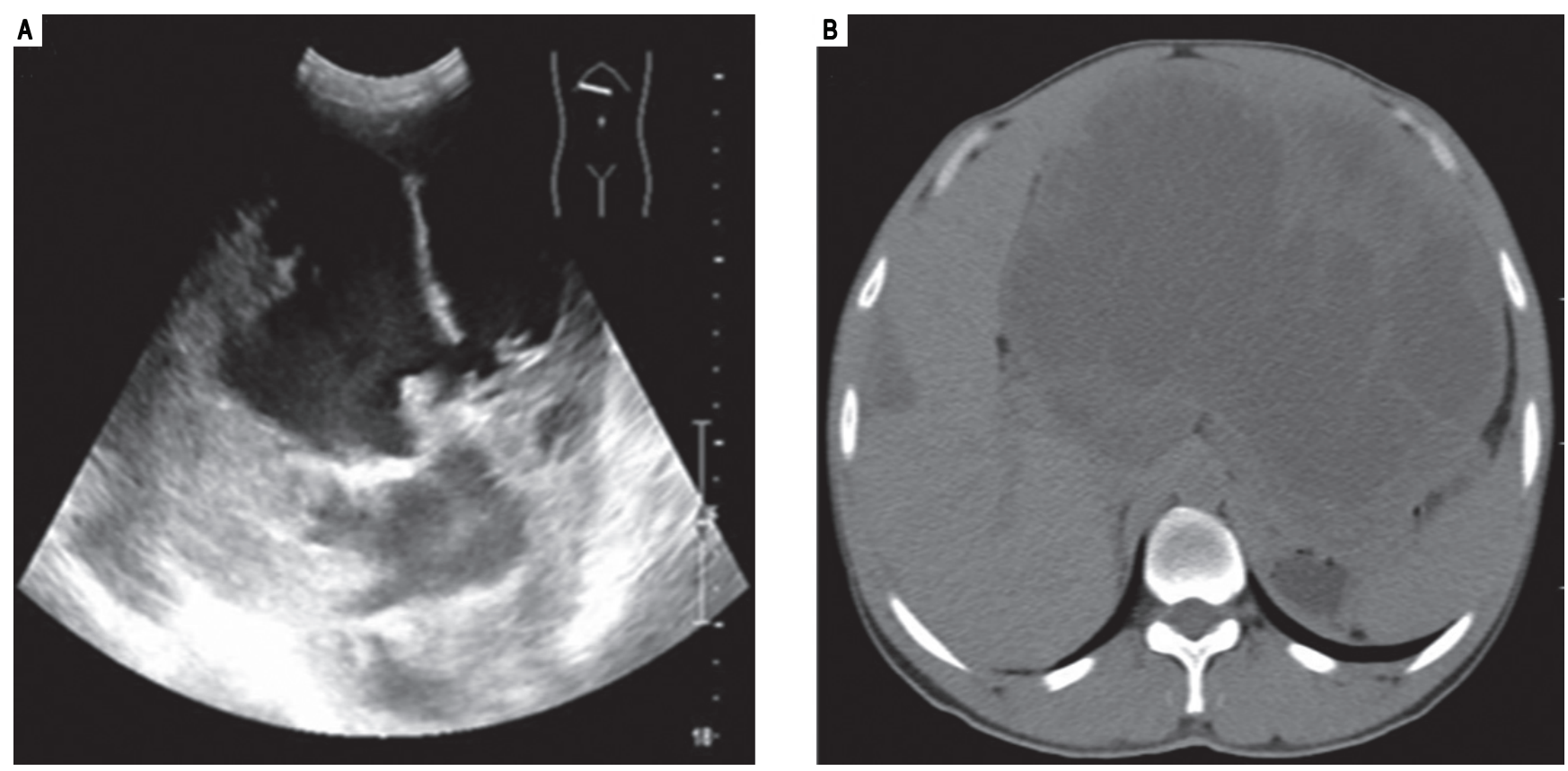

Figure 1. Ultrasound examination (A) revealed a mixed echo mass within the left lobe of the liver and the tumor was too large to be measured by this method. Computerized tomography examination (B) revealed a large mass approximately $21.0 \mathrm{~cm} \times 16.0 \mathrm{~cm}$ with a mixed density and an irregular border in the left hepatic lobe.

(Figure 2). The pseudocysts/pseudoglands within the cribriform areas were filled with loose myxoid to dense eosinophilic base membrane-like material (Figures 2B and $2 \mathrm{C}$ ). There were occasional true small glandular structures within the cribriform areas (Figure 2C). A minor component of solid growth (Figure 2D) and tubular structures (Figure 2E) was present. The stroma showed abundant hyalinization which strangulated the tumor cells into anastomosing trabeculae (Figure 2F). The tumor cells had oval to angulated hyperchromatic nuclei with scant cytoplasm and indistinct cell border. There was mild nuclear pleomorphism (Figure 2). The mitotic count was $1 / 10$ high power fields and there was no atypical mitosis. Focal tumor cell necrosis was present (5\%). Immunohistochemically both luminal and abluminal cells showed diffuse positivity for CK7 and CK19, and their staining intensity was stronger in the luminal cells than that in the abluminal cells (Figure 3A). Cytokeratin CK8/18 was diffusely positive in the luminal cells but only focal weakly positive in the abluminal cells. P63 staining labeled the abluminal cells but not the luminal cells (Figure 3B) whereas CD117 showed an opposite labeling pattern (Figure 3C). Ki-67 proliferation was about $10-15 \%$ (Figure $3 \mathrm{~F}$ ).

According to the most recent World Health Organization (WHO) diagnostic criteria, the major diagnostic histological criteria for ACC include biphasic cell population (luminal and abluminal cells) and variable growth patterns including tubules, solid and cribriform architecture. ${ }^{10}$ The tumor in our case demonstrated biphasic cell population with predominantly cribriform growth with focal solid and tubular structures. Therefore, this tumor fulfills the histologic criteria for ACC. ${ }^{10}$ The histologic diagnosis was further confirmed by immunohistochemical stains which labeled two distinct cell populations (luminal cells CK8 / 18 diffuse+, p63-, CD117+; abluminal cells CK8 / 18 focal + , p63+, CD117-).

This tumor also invaded through the liver capsule and involved adjacent diaphragm. The omentum also contained several tumor nodules ranging from 1.2 to $5.4 \mathrm{~cm}$. The tumor in the diaphragm and omentum showed similar histologic features to that in the liver.

After the diagnosis of adenoid cystic carcinoma was made, the patient underwent whole body PET-CT which revealed no tumor in other body sites including salivary glands, other head and neck sites, lung and prostate, etc. Based on these findings, his liver tumor was most consistent with a primary hepatic adenoid cystic carcinoma.

After the surgery, the patient refused to receive chemotherapy and radiation therapy due to financial issue. On his lobe of followup at 26 months after surgery, magnetic resonance imaging showed tumor recurrence in the right lobe of his liver, diaphragm, omentum and retroperitoneum. There was no disease in other body sites on imaging studies. The patient died of disease at 33 months after surgery. 

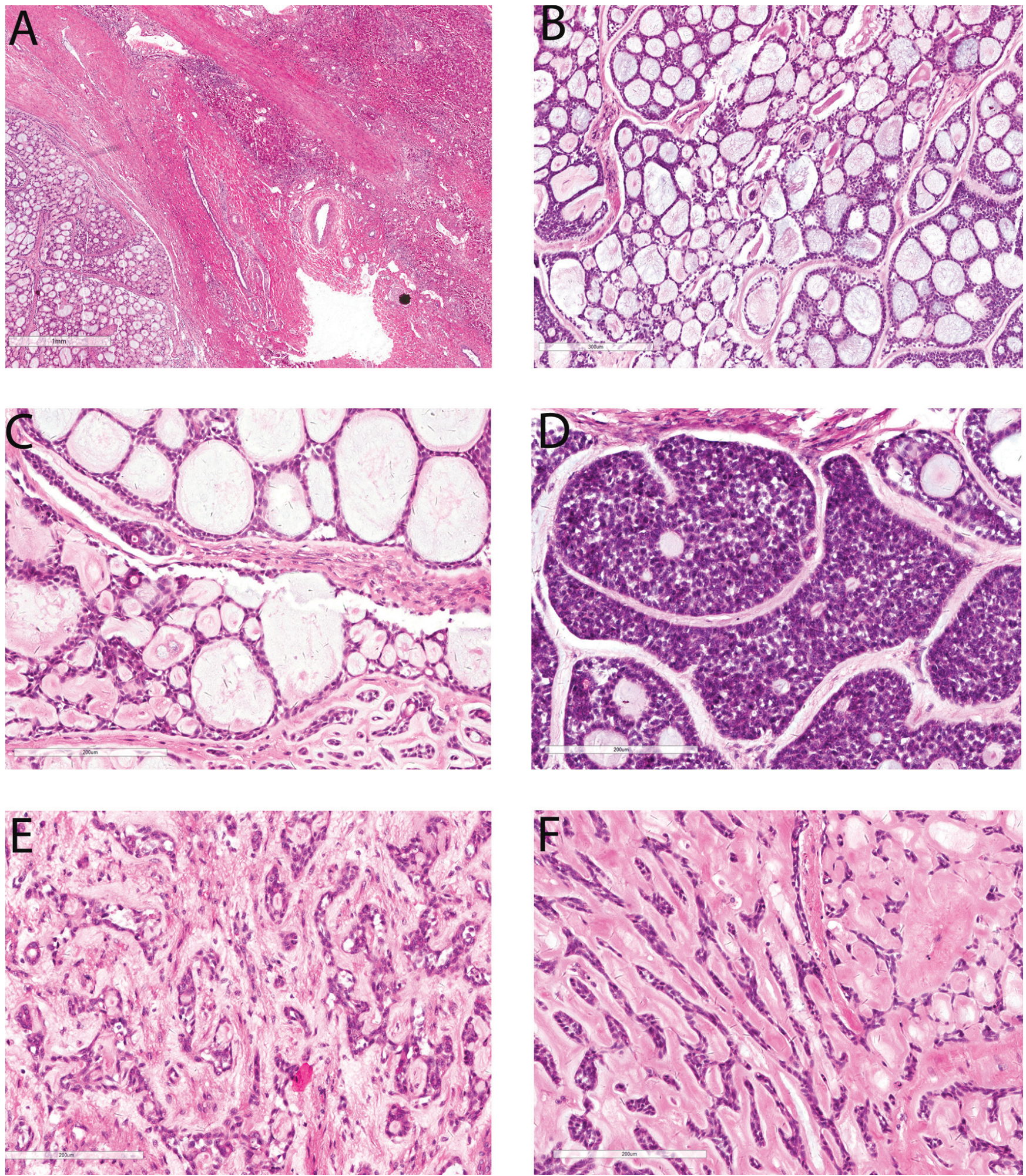

Figure 2. Microscopic features of primary hepatic adenoid cystic carcinoma. There is a thick capsule between the tumor (left lower) and the adjacent liver tissue (right upper, $\boldsymbol{A}, 20 \mathrm{x})$. The predominant growth pattern of this tumor is cribriform (B, 100x). The cystic spaces within the cribriform area are predominantly pseudocysts filled with loose myxoid material $(\boldsymbol{B}, 100 x)$ and eosinophilic base membrane-like material $(\boldsymbol{C}, 200 x)$ but there are occasional true small glands (C, 200x). This tumor contains only focal solid growth (D,200x) and tubular structures (E, 200x). There is abundant hyalinization in the stroma in some areas which compressed the tumor cells into anastomosing strands $(\boldsymbol{F}, 200 x)$. 

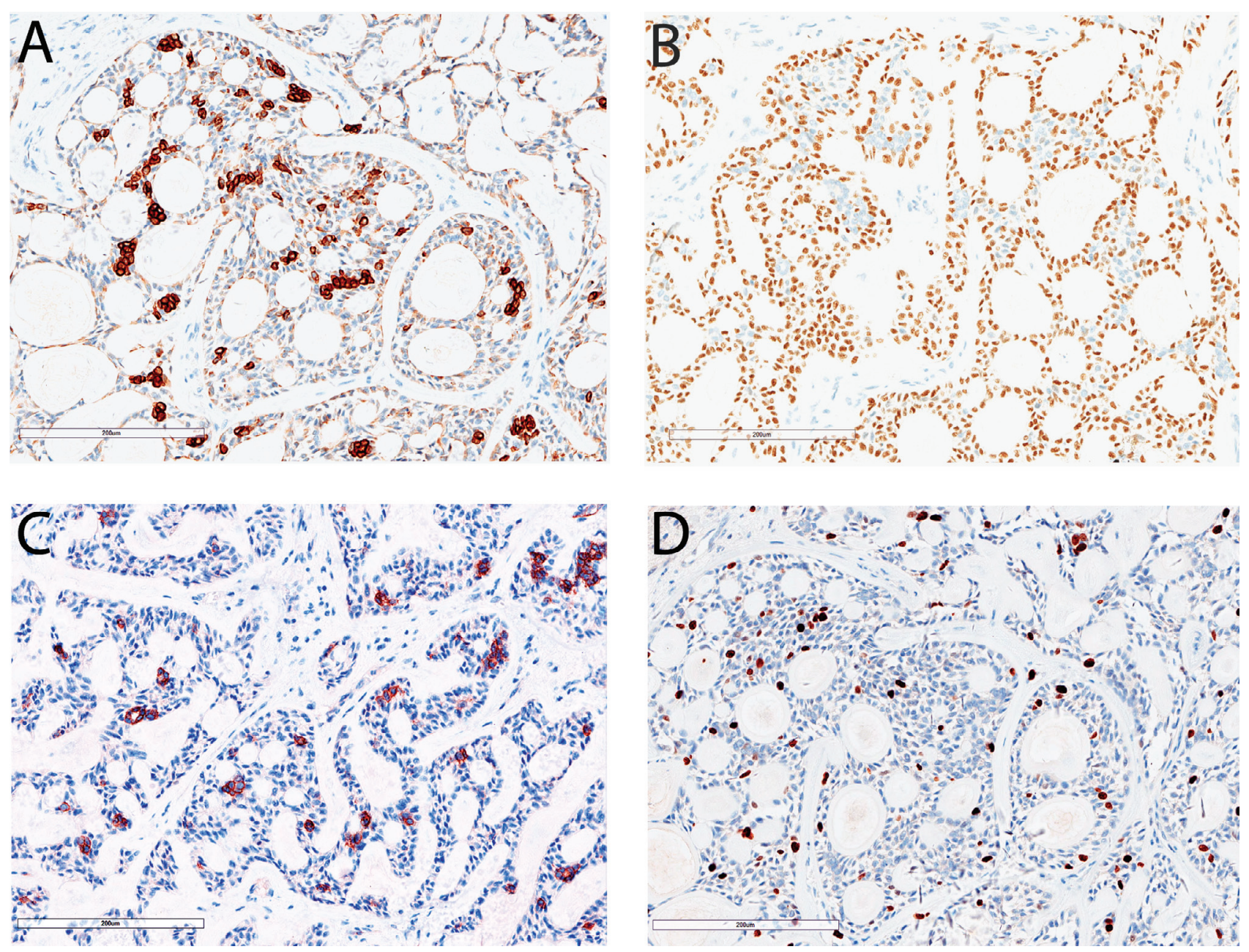

Figure 3. Immunohistochemical staining results of primary hepatic adenoid cystic carcinoma. Cytokeratin 7 is diffusely positive in the tumor cells and shows stronger staining in the luminal cells than abluminal cells (A, 200x). P63 staining labels abluminal cells but not luminal cells (B, 200x). CD117 staining labels luminal cells but not abluminal cells (C, 200x). The Ki-67 proliferation index in this tumor is about $10-15 \%$ (D, 200x).

\section{DISCUSSION}

In this report, we presented a unique case of ACC in the liver. The tumor invaded the liver capsule and also involved adjacent diaphragm and omentum. This patient had no tumor in other sites including the head and neck region, upper respiratory tract and genital tract at the time of initial presentation and followup at 26 months on imaging study. This tumor demonstrated typical morphologic features and immunohistochemical profile of ACC, according to the WHO criteria. ${ }^{10}$ This case was reviewed in the departmental consensus conference and was also seen by two pathologists in consultation in two other outside hospitals.

Adenoid cystic carcinoma is a relatively uncommon tumor, most commonly in the salivary glands but it may also occur in other body sites including upper aerorespiratory tract, breast and the genital tract etc. It is very rare as a pri- mary tumor in other sites. In the liver, only one primary adenoid cystic carcinoma has been reported in the English literature. ${ }^{9}$ The patient in that study ${ }^{9}$ was a 21 -years old female who presented with a $30 \mathrm{~cm}$ mass during her pregnancy. The tumor almost occupied the whole liver. In our case, the tumor was $21 \mathrm{~cm}$ in size. In the liver, the tumor can grow to a large size probably due to the intrabdominal location that can give the tumor more room to grow before symptoms became evident.

We favor our case is a primary ACC of the liver. Our case is the second case of primary ACC in the literature. We favor a primary ACC of the liver based on the following facts. Firstly, this tumor formed a single mass in the liver at the time of initial surgery and there was no evidence of tumor in any other organ including lung and salivary gland at that time. Metastasis typically forms multiple nodules within the liver. Secondly, during his followup at 
26 months (with imaging study), there was still no tumor in another organ except recurrence in the liver, diaphragm, omentum and retroperitoneum. Thirdly, other types of salivary gland type tumors have been reported as primary tumors in the liver and bile duct system including mucoepidermoid carcinoma, myoepithelial carcinoma, and epithelial-myoepithelial carcinoma. ${ }^{11-17}$ Primary mucoepidermoid carcinoma has been also reported in the pancreas and ascending colon. ${ }^{18,19}$ There are two possible explanation for the histogenesis of primary salivary gland type tumors in the liver, pancreatobiliary tract and intestinal tract:

- Stem / Reserve cells transdifferentiate into salivary gland type tumors during malignant transformation (more likely). ${ }^{19}$

- These tumors may arise from ectopic salivary gland tissue.

Salivary gland heterotopia/choristoma is typically seen in the head and neck region but it can be seen in the gastrointestinal tract including esophagus, small bowel, colon and rectum. ${ }^{20-23}$ So far there has been no report of salivary gland heterotopia/choristoma in the liver and bile duct system, but this possibility cannot be entirely excluded.

The major differential diagnosis for our case is a metastatic adenoid cystic carcinoma from another site. Among the adenoid cystic carcinomas in the head and neck region, a significant percentage of them (20 to 50\%) will develop distant metastasis at the time of presentation or in the subsequent disease course. ${ }^{24-27}$ Lung is the most common site of metastasis followed by bone whereas brain and liver are much less common sites for metastasis. ${ }^{24-30}$ Liver is rarely the only site of metastasis. ${ }^{24-30}$ Liver metastasis may be the first sign of presentation. ${ }^{15-16}$ Besides adenoid cystic carcinoma of salivary glands, adenoid cystic carcinoma from other sites such as vulva, ${ }^{31}$ trachea, ${ }^{32}$ lacrimal gland ${ }^{33}$ has also been reported to metastasize to the liver. Our patient did not have any tumor in other sites on imaging studies at the time of treatment and on followup (26 months after the surgery). These findings favor the diagnosis of a primary hepatic ACC as discussed above.

Adenoid cystic carcinoma is a slow growing tumor but it shows a relentless and progressive disease with 10 -year survival rate less than $50 \% .{ }^{27}$ Surgery is the main treatment. The postoperative radiotherapy is recommended if the surgical margin is positive. Because of a poor response, chemotherapy was not typically recommended as a therapeutic option. ${ }^{27}$ Tumor stage and histologic grade are the two most important prognostic factors for adenoid cystic carcinoma in the head and neck region. ${ }^{26,27,34}$ Solid growth pattern was associated with a worse prognosis. ${ }^{26,27,34}$ Our case showed very focal solid growth $(<5 \%)$ and it had a large size and invaded through liver capsule into diaphragm and omentum, indicating an advanced stage. The disease recurred at 26 months and died at 33 months after surgery, speaking itself for its relentless and progressive disease course.

In summary, we presented a unique case of ACC in a 44 years old male patient in his liver and we favor this is a primary hepatic ACC. The carcinoma demonstrated typical morphologic and immunohistochemical profile of adenoid cystic carcinoma.

\section{ABBREVIATIONS}

- ACC: adenoid cystic carcinoma.

- ALT: alanine transaminase.

- AST: aspartate aminotransferase.

- GGT: gamma-glutamyl transferase.

\section{CONFLICT OF INTEREST}

The authors declares that there is no conflict of interest regarding the publication of this article.

\section{FUNDING}

This work was supported by the National Natural Science Foundation of China (No. 81370661) and the Natural Science Foundation of Henan Province of China (No. 102300410038).

\section{REFERENCES}

1. Bonaparte JP, Hart R, Trites J, Taylor MS. Incidence of adenoid cystic carcinoma in nova scotia: 30 -year populationbased epidemiologic study. J Otolaryngol Head Neck Surg 2008; 37: 642-8.

2. Ellington $\mathrm{CL}$, Goodman M, Kono SA, Grist W, Wadsworth $\mathrm{T}$, Chen AY, Owonikoko T, et al. Adenoid cystic carcinoma of the head and neck: Incidence and survival trends based on 1973-2007 Surveillance, Epidemiology, and End Results data. Cancer 2012; 118: 4444-51.

3. Johns ME, Batsakis JG. Adenoid cystic carcinoma of the lacrimal gland. J Laryngol Otol 1975; 89: 641-4.

4. Hajdu SI, Huvos AG, Goodner JT, Foote FW, Beattie EJ. Carcinoma of the trachea: a clinicopathologic study of 41 cases. Cancer 1970; 25: 1448-56.

5. Moran CA, Suster S, Koss MN. Primary adenoid cystic carcinoma of the lung. A clinicopathologic and immunohistochemical study of 16 cases. Cancer 1994; 73: 1390-7.

6. Vranic S, Bender R, Palazzo J, Gatalica Z. A review of adenoid cystic carcinoma of the breast with emphasis on its molecular and genetic characteristics. Hum Pathol 2013; 44: 301-9.

7. Iczkowski KA, Ferguson KL, Grier DD, Hossain D, Banerjee SS, McNeal JE, Bostwick DG. Adenoid cystic/basal cell carcinoma of the prostate: clinicopathologic findings in 19 cases. Am J Surg Pathol 2003; 27: 1523-9.

8. Woida FM, Ribeiro-Silva A. Adenoid cystic carcinoma of the 
Bartholin gland: an overview. Arch Pathol Lab Med 2007; 131: 796-8.

9. Ziarkiewicz-Wroblewska B, Gornicka B, Bogdanska M, Otto W, Wróblewski T, Krawczyk M, Wasiutynski A. Carcinoma adenoides cysticum as a primary neoplasm most probably derived from biliary ducts-case report. Med Sci Monit 2001; 7(Suppl. 1): 123-6.

10. Stenman G, Licitra L, Said-Al-Naief, van Zante A, Yarbrough W.G. Adenoid cystic carcinoma. In: El-Naggar AK, Chan JKC, Grandis JR, Takata T, Slootweg PJ (eds.). WHO classification of head and neck tumours. 4th Ed. Lyon: International Agency for Research On Cancer 2017; p. 164-5.

11. Choi D, Kim H, Lee KS, Lee KG, Park CK. Mucoepidermoid carcinoma of the liver diagnosed as a liver abscess: report of a case. Surg Today 2004; 34: 968-72.

12. Hiyashi I, Tomoda H, Tanimoto M, Furusawa M, Katsuda $Y$, Shirai S, Morimatsu M. Mucoepidermoid carcinoma arising from a preexisting cyst of the liver. J Surg Oncol 1987; 36: 122-5.

13. Moul AE, Bejarano PA, Casillas J, Levi JU, Garcia-Buitrago MT. Mucoepidermoid carcinoma of the intrapancreatic common bile duct: immunohistochemical profile, prognosis and review of the literature. Case Rep Pathol 2013; 2013: 192458. doi: $10.1155 / 2013 / 192458$

14. Koo J, Ho J, Wong J, Ong GB. Mucoepidermoid carcinoma of the bile duct. Ann Surg 1982; 196: 140-8.

15. Ho JC. Two cases of mucoepidermoid carcinoma of the liver in Chinese. Pathology 1980; 12: 123-8.

16. Hassan W, Nishi J, Tomiyasu S, Urakado T, Haraoka K, Yamanaka T, Fujiyama S. Ususual biliary myoepithelial carcinoma in liver-case report and immunohistochemical study. Int $J$ Clin Exp Pathol 2014; 7: 2647-53.

17. Liu Y, Sang XT, Gao WS, Mao YL, Liu YW, Liu HF, Yang ZY, et al. The first case of primary epithelial-myoepithelial carcinoma in the liver. Zhonghua Wai K Za Zhi (Chinese Journal of Surgery) 2006; 44: 1477-9.

18. Ma R, Yu YQ, Li JT, Peng SY. Mucoepidermoid carcinoma of the pancreas: a case report and a review of literature. $J$ Res Med Sci 2012; 17: 886-9.

19. Sato H, Kuroda M, Maruta M, Maeda K, Koide Y. Mucoepidermoid carcinoma of the ascending colon: report of a case. Surg Today 2002; 32: 1004-7.

20. Wang C, Chen L, Guo W, Zhu X, Liu Z. Salivary gland choristoma in the esophagus. Endoscopy 2014; 46(Suppl. 1) UCTN: E658-9. Doi: 10.1055/s-0034-1390842.

21. Olajide TA, Agodirin SO, Ojewola RW, Arkanbi OO, Solaja TO, Odesanya JO, et al. Jenunal choristoma: a very rare cause of abdominal pain in children. Case Rep Surg 2014; 2014: 863647. Doi: 10.1155/2014/863647.

22. Maffini F, Vingiani A, Lepanto D, Fiori G, Viale G. Salivary gland choristoma in large bowel. Endoscopy 2012; 44(Suppl. 2) UCTN: E13-4. Doi: 10.1055/s-0031-1291498.

23. Downs-Kelly E, Hoschar AP, Prayson RA. Salivary gland heterotopia in the rectum. Ann Diagn Pathol 2003; 7: 124-6.
24. Spiro RH, Huvos AG, Strong EW. Adenoid cystic carcinoma of salivary origin. A clinicopathologic study of 242 cases. Am J Surg 1974; 128: 512-20.

25. van der Wal JE, Becking AG, Snow GB, van der Waal I. Distant metastases of adenoid cystic carcinoma of the salivary glands and the value of diagnostic examinations during follow-up. Head Neck 2002; 24: 779-83.

26. Sung MW, Kim KH, Kim JW, Min YG, Seoing WJ, Roh JL, Lee SJ, et al. Clinicopathologic predictors and impact of distant metastasis from adenoid cystic carcinoma of the head and neck. Arch Otolaryngol Head Neck Surg 2003; 129: 1193-97.

27. Bradley PJ. Adenoid cystic carcinoma of the head and neck: a review. Curr Opin Otolaryngol Head Neck Surg 2004; 12: 127-32.

28. He S, Li P, Zhong Q, Hou L, Yu Z, Huang Z, Chen X, et al. Clinicopathologic and prognostic factors in adenoid cystic carcinoma of head and neck minor salivary glands: A clinical analysis of 130 cases. Am J Otolaryngol 2016; pii: S01960709(16)30253-8. Doi: 10.1016/j.amjoto.2016.11.014 [Epub ahead of print].

29. Deshpande AH, Kelkar AA. Hepatic metastasis as an initial manifestation of salivary adenoid cystic carcinoma: Cytologic diagnosis. Diagn Cytopathol 2009; 37: 45-7.

30. Spolverato G, Fite J, Bishop J, Argani P, Pawlik TM. Liver metastasis as the initial presentation of adenoid cystic carcinoma. Dig Dis Sci 2014; 59: 2004-6.

31. Shahabi S, Nathan LM, Chanana C, Garett W, Zheng W, Rutherford TJ. Liver metastasis in a case of adenoid cystic carcinoma of the Bartholin's gland: a rare presentation. Arch Gynecol Obstet 2009; 279: 747-50.

32. Zeidan BA, Abu Hilal M, Al-Gholmy M, El-Mahallawi $\mathrm{H}$, Pearce NW, Primrose JN. Adenoid Cystic Carcinoma of the lacrimal gland metastasising to the liver: report of a case. World J Surg Oncol 2006; 4: 66.

33. Park I, Lim SN, Yoon DH, Park H, Sun B, Lee PH, Hwang I, et al. Metastasectomy for hepatic metastases from adenoid cystic carcinoma of the trachea. Gut Liver 2009; 3: 127-9.

34. Perzin KH, Gullane P, Clairmont AC. Adenoid cystic carcinomas arising in salivary glands: a correlation of histologic features and clinical course. Cancer 1978; 42: 265-82.

Correspondence and reprint resquest: Dengfeng Cao, M.D. Ph.D.

Department of Pathology and Immunology.

Washington University School of Medicine.

660 S Euclid Ave Campus Box 8118. Saint Louis, MO 63110, United States of America.

Tel.: 1-314-747-5007. Fax: 1-341-362-8950 E-mail: dcao@path.wustl.edu 